\title{
PROTEOLYTIC PROCESSING OF THE POLYPROTEIN ENCODED BY ORF1b OF THE CORONAVIRUS INFECTIOUS BRONCHITIS VIRUS (IBV)
}

\author{
D. X. Liu, ${ }^{1,2}$ S. Shen, ${ }^{1}$ H. Y. Xu, ${ }^{1}$ and T. D. K. Brown ${ }^{2}$ \\ 'Institute of Molecular Agrobiology \\ 59A The Fleming \\ 1 Science Park Drive \\ Singapore 118240 \\ ${ }^{2}$ Division of Virology \\ Department of Pathology \\ University of Cambridge \\ Tennis Court Road \\ Cambridge, CB2 1QP, United Kingdom
}

\section{ABSTRACT}

We present here evidence demonstrating that four previously predicted Q-S(G) cleavage sites, encoded by the IBV sequences from nucleotide 15129 to 15134,16929 to 16934,18492 to 18497 , and 19506 to 19511 , respectively, can be recognised and transcleaved by the $3 \mathrm{C}$-like proteinase. Five mature products with sizes of approximately 100 $\mathrm{kDa}, 65 \mathrm{kDa}, 63 \mathrm{kDa}, 42 \mathrm{kDa}$ and $35 \mathrm{kDa}$ are released from the ORF1b polyprotein by the $3 \mathrm{C}$-like proteinase-mediated cleavage at these positions. Meanwhile, expression of plasmids containing only the ORF1b region showed no autocleavage of the polyproptein encoded, suggesting that the $3 \mathrm{C}$-like proteinase may be the sole proteinase involved in processing of the $1 \mathrm{~b}$ polyprotein. These data may therefore represent a complete processing map of the polyprotein encoded by ORF1b of mRNA1.

\section{INTRODUCTION}

Three proteinase domains, including two overlapping papain-like proteinase domains encoded by the IBV sequences from nucleotide 4242 to 5553 and one trypsin-like 
proteinase domain of the picornavirus $3 \mathrm{C}$ proteinase group (3C-like proteinase) encoded between nucleotides 8937 and 9357, have been predicted to be encoded by ORF 1a (Gorbalenya et al., 1989; Lee et al., 1991). The papain-like proteinase domains were demonstrated to be involved in proteolytic processing of the la polyprotein to an $87 \mathrm{kDa}$ mature viral product (Liu et al., 1995). However, it is likely that only a limited number of cleavages may be mediated by this proteinase. More important role in proteolytic processing of the mRNAl-encoding polyprotein may be played by the $3 \mathrm{C}$-like proteinase domain, as more than ten $\mathrm{Q}-\mathrm{S}(\mathrm{G})$ dipeptide bonds located in the $1 \mathrm{a} / 1 \mathrm{~b}$ polyproteins are predicted to be the cleavage sites for this proteinase (Gorbalenya et al., 1989). Indeed, we have reported the identification of a $100 \mathrm{kDa}$ polymerase domain-containing protein, released from the $1 \mathrm{a} / 1 \mathrm{~b}$ polyprotein by the $3 \mathrm{C}$-like proteinase-mediated cleavage at two predicted Q-S dipeptide bonds (Liu et al., 1994; Liu and Brown, 1995). More recently, a $10 \mathrm{kDa}$ mature viral product encoded by ORF 1a from nucleotide 11545 to 11878 was shown to be cleaved from the la polyprotein by the same proteinase (Liu et al., 1997).

In this communication, we report experiments designed to map the $3 \mathrm{C}$-like protienase-dependent cleavage sites in the polyprotein encoded by the ORF $1 \mathrm{~b}$ region of mRNA1. Three ORF 1 b-specific antisera, V58, V60 and V17 were used in the study. Cotransfection, deletion and site-directed mutagenesis studies demonstrated that four previously predicted $\mathrm{Q}-\mathrm{S}(\mathrm{G})$ cleavage sites, encoded by the IBV sequences from nucleotide 15129 to 15134,16929 to 16934,18492 to 18497 and 19506 to 19511 , respectively, were recognised and cleaved by the $3 \mathrm{C}$-like proteinase to release five mature products with sizes of approximately $100 \mathrm{kDa}, 65 \mathrm{kDa}, 63 \mathrm{kDa}, 42 \mathrm{kDa}$ and $35 \mathrm{kDa}$. Information gained from this study could be used to guide further identification and characterisation of the ORF 1 b-specific viral products.

\section{MATERIALS AND METHODS}

\subsection{Transient Expression of IBV Sequences in Vero Cells Using a Vaccinia-T7 Expression System}

Open reading frames placed under control of the T7 promoter were expressed transiently in eukaryotic cells using the vaccinia virus-T7 expression system (Fuerst $e t$ al., 1986).

\subsection{Polymerase Chain Reaction (PCR)}

Appropriate primers and template DNAs were used in amplification reactions with Pfu DNA polymerase (Stratagene) under standard buffer conditions with $2 \mathrm{mM} \mathrm{MgCl}$. PCR reaction conditions were 30 cycles of $95^{\circ} \mathrm{C}$ for 45 seconds, $\mathrm{X}^{\circ} \mathrm{C}$ for 45 seconds and $72^{\circ} \mathrm{C}$ for $\mathrm{X}$ minutes. The annealing temperature and the extension time were adjusted according to the melting temperature of the primers used and the length of the PCR fragments synthesised.

\subsection{Site-Directed Mutagenesis}

Site-directed mutagenesis was carried out, as previously described (Liu et al., 1994), using single stranded DNA templates prepared from pIBV1b5 and appropriate oligonucleotide primers. 
Substitution mutation of the $\mathrm{Q}^{1491(\mathrm{lb})}-\mathrm{G}^{1492(1 \mathrm{~b})}$ dipeptide bond was introduced, as previously described (Liu et al., 1997), by two rounds of PCR with two pairs of primers.

\subsection{Radioimmunoprecipitation}

Plasmid DNA-transfected Vero cells were lysed with RIPA buffer $(50 \mathrm{mM}$ Tris $\mathrm{HCl}$, $\mathrm{pH} 7.5,150 \mathrm{mM} \mathrm{NaCl}, 1 \%$ sodium deoxycholate, $0.1 \%$ SDS) and pre-cleared by centrifugation at $12,000 \mathrm{rpm}$ for 5 minutes at $4^{\circ} \mathrm{C}$ in a microfuge. Immunoprecipitation was carried out as described previously (Liu et al., 1994).

\subsection{SDS-Polyacrylamide Gel Electrophoresis}

SDS-polyacrylamide gel electrophoresis (SDS-PAGE) of virus polypeptides was carried out with $10 \%$ polyacrylamide gels (Laemmli, 1970). Labelled polypeptides were detected by autoradiography or fluorography of dried gels.

\subsection{Construction of Plasmids}

Plasmid pIBV1b3, which covers the IBV sequence from nucleotide 15135 to 16931 , was constructed by cloning an NcoI/BamHI digested-PCR fragment into NcoI/BamHI digested pKT0 (Liu et al., 1994). An artificial AUG initiation codon in an optimal context (ACCAUGG) located immediately upstream of the viral sequence and a UAG termination codon located immediately downstream of the viral sequence were meanwhile introduced by PCR. The sequence of the upstream PCR primer is 5'-CGACTTCCATG GCTTGTGGCGTT-3', and the sequence of the downstream primer is 5'-CCAAAGGATCCTATTGCAGACTTG-3'. Plasmid pIBV1b4 was constructed by cloning an SnaBI/DraI fragment containing the IBV sequence from nucleotide 18930 to 20874 into EcoRV/SmaI digested pKT0, and selected by nucleotide sequencing. Plasmid pIBV1b5 was made by cloning an NcoI/BamHI digested PCR fragment, which covers the IBV sequence from nucleotide 16932 to 20490, into NcoI-BamHI digested pKT0. An artificial AUG initiation codon in an optimal context (ACCAUGG) located immediately upstream of the viral sequence was introduced by PCR. The sequence of the upstream PCR primer is 5'-ACAAGTCCATGGGTACAGGTT-3', and the sequence of the downstream primer is 5'-GCACCCCCGGGATCCTGCCAAC-3'.

Plasmids pIBV3C and pIBV5, which cover the IBV sequence from nucleotide 8871 to 9786 and from 10752 to 16980 , respectively, were described previously (Liu et al., 1994; Liu et al., 1997).

Plasmid pIBV20 was made by cloning a 3,665 bp PCR fragment, which contains the IBV sequence from nucleotide 16841 to 20506, into EspI- and BamHI-digested pIBVIb3 (EspI cuts the IBV sequence at nucleotide position 16840, the BamHI site was located immediately downstream of the IBV sequence and was introduced by PCR with primer 5'GCACCCCCGGGATCCTGCCAAC-3'.

Plasmid pIBV14Æ1Q ${ }^{891(1 b)}$-E, which covers the IBV sequences from nucleotide 8693 to 16980 with deletions of the regions from nucleotide 9911 to 12227 and from 15537 to 16788 , respectively, and contains a $\mathrm{Q}^{891(1 \mathrm{~b})}$ to $\mathrm{E}$ mutation, was described previously (Liu and Brown, 1995). Plasmid pIBV21, which covers the IBV sequences from nucleotide 8693 to 17630 with the two deletions in pIBV14Æ1Q $\mathrm{Q}^{891(\mathrm{bb})}$-E and contains substitution mutations at both the $\mathrm{Q}^{891(\mathrm{bb})}-\mathrm{S}^{892(\mathrm{~b})}$ and $\mathrm{Q}^{1491(\mathrm{lb})}-\mathrm{S}^{1492(\mathrm{~b})}$ sites, was constructed as follows. A 1,242 bp PCR fragment, which covers the IBV sequence from nucleotide 16788 
to 17630 and contains a $\mathrm{Q}^{1491(1 \mathrm{~b})}$ to $\mathrm{M}^{1491(\mathrm{lb})}$ mutation, was generated by two rounds of PCR. The sequence of the oligonucleotide primer used to introduce the mutation is 5'ACAAGTCCCATGGGTACAGGTT-3', and the sequence of the complementary primer is 5'-AACAAACCTGTACCCATGGGAC-3'. This PCR fragment was then digested with PstI (which cuts the IBV sequence at nucleotide 15537), gel-purified and ligated into PstISmaI digested pIBV14Æ1Q ${ }^{891(1 b)}$-E, giving plasmid pIBV21. The construct was selected by restriction digestion with $\mathrm{NcoI}$ and confirmed by nucleotide sequencing.

Two mutant constructs, $\mathrm{pIBV} 1 \mathrm{~b} 5 \mathrm{Q}^{2350(1 \mathrm{~b})}-\mathrm{E}$ and $\mathrm{pIBV} 1 \mathrm{~b} 5 \mathrm{Q}^{2012(\mathrm{lb})}-\mathrm{E}$, with alterations at the putative $\mathrm{Q}^{2350(1 \mathrm{~b})}-\mathrm{S}^{2351(1 \mathrm{~b})}$ and $\mathrm{Q}^{2012(1 \mathrm{~b})}-\mathrm{S}^{2013(1 \mathrm{~b})}$ cleavage sites, respectively, were made by site-directed mutagenesis with the single stranded DNA templates prepared from plasmid pIBV1b5. The sequences of the oligonucleotide primers used to introduce the mutations are: 5'-TCCACAGCTTGAATCAGCATG-3' and 5'-TTCAGCTCTCGAGTCTATC GAC-3', respectively.

\section{RESULTS}

\subsection{Characterisation of Two Antisera Raised against Bacterial-Viral Fusion Proteins Containing the C-Terminal Regions of the ORF 1b-Encoding Polyprotein}

We have recently reported the identification of a $100 \mathrm{kDa}$ protein encoded by the IBV sequence from nucleotide 12313 to 15131 in IBV-infected Vero cells with an ORF 1b-specific antiserum V58 (Liu et al., 1994; Liu and Brown, 1995). No viral products, however, were detected by using two other ORF 1 b-specific antisera, V60 and V17 (Liu et al., 1994; Liu, unpublished observations). Antisera V60 and V17 were raised in rabbits against $\beta$-galactosidase-IBV fusion proteins containing the IBV sequences encoded from nucleotide 16066 to 16783 and from 19154 to 20649, respectively (Figure 1a). The specificity and affinity of these two antisera for their target proteins were tested by immunoprecipitation against in vitro synthesised ORF $1 \mathrm{~b}$ products.

As the results shown in Figure 1b, expression of plasmid pIBV1b3, which contains the IBV sequence from nucleotide 15132 to 16932 , led to the synthesis of a polypeptide of approximately $65 \mathrm{kDa}$, consistent with the calculated molecular weight of $69 \mathrm{kDa}$ of the full-length product encoded by this construct. Immunoprecipitation study showed that the $65 \mathrm{kDa}$ protein can be efficiently and specifically precipitated by antiserum V60 (Figure $1 \mathrm{~b})$.

To characterise antiserum V17, plasmid pIBV1b5, which contains IBV sequence from nucleotide 16930 to 20874 , was linearised at different positions by restriction enzymes (Figure 1a), and transcribed and translated in the TnT system. As shown in Figure 1c, transcription and translation of SacI-digested pIBV1b5 led to the synthesis of a polyprotein of approximately $140 \mathrm{kDa}$, representing the full-length product encoded by this construct. Transcription and translation of BstBI-, MboII- and StuI-digested pIBV1b5 resulted in the synthesis of proteins of approximately $110 \mathrm{kDa}, 98 \mathrm{kDa}$ and $85 \mathrm{kDa}$, respectively (Figure 1c). Immunoprecipitation studies showed that the $140 \mathrm{kDa}$ full-length product as well as the $110 \mathrm{kDa}$ and $98 \mathrm{kDa}$ proteins could be efficiently precipitated by antiserum V17 (Figure 1c). However, the $85 \mathrm{kDa}$ protein could not be precipitated by the same antiserum. These results confirm the specific recognition of the target products by the antiserum. 


\subsection{Transient Expression of ORF 1b in Eukaryotic Cells}

Plasmids covering the ORF $1 \mathrm{~b}$ region were then expressed in Vero cells by using the vaccinia virus-T7 expression system, and analysed by immunoprecipitation with three ORF-1b-specific antisera. As can be seen, expression of plasmid pIBV5, which contains the IBV sequence from nucleotide 10752 to 16980 , resulted in the detection of two major protein species with apparent molecular weights of approximately $60 \mathrm{kDa}$ and $200 \mathrm{kDa}$, respectively, representing the ORF la termination product and the full-length product encoded by the construct (also see Liu et al., 1994). The $200 \mathrm{kDa}$ full-length protein can be immunoprecipitated by both antisera V58 and V60 (Figure 2). No $100 \mathrm{kDa}$ and any other cleavage products were detected (Figure 2). Similarly, expression of pIBV20, which covers the IBV sequence from nucleotide 15135 to 20506 , led to the detection of a product with an apparent molecular weight of approximately $190 \mathrm{kDa}$, representing the full-length polyprotein encoded by this construct. This $190 \mathrm{kDa}$ protein can be immunoprecipited by both antisera V60 and V17 (Figure 2). No other products were detected by either antiserum (Figure 2), confirming that there is no autoprocessing of the polyprotein encoded by this region of ORF $1 b$.

\subsection{Determination of the C-Terminal Cleavage Site of the Putative Metal-Binding and RNA-Helicase Protein}

Data presented above suggest that there is no autocleavage of the polyprotein encoded by ORF $1 b$. In a previous report, we confirmed that a previously predicted $Q S\left(Q^{891(1 b)} S^{892(1 b)}\right)$ dipeptide bond is the C-terminal cleavage site of the $100 \mathrm{kDa}$ protein (Liu and Brown, 1995). Three other QS(G) dipeptide bonds in the $1 \mathrm{~b}$ polyprotein were also predicted to be the cleavage sites of the $3 C$ proteinase (Gorbalenya et al., 1989). The first of these sites is the $\mathrm{Q}^{1491(\mathrm{lb})} \mathrm{G}^{1492(1 \mathrm{~b})}$ dipeptide bond. Substitution of the $\mathrm{Q}^{1491(\mathrm{lb})}$ residue with an $\mathrm{M}$ was therefore carried out to test if this is a scissile bond of the $3 \mathrm{C}$-like proteinase. As shown in Figure 3, expression of pIBV14 $1 \mathrm{Q}^{891(\mathrm{bb})}$-E led to the detection of a protein of $125 \mathrm{kDa}$ (see also Liu and Brown, 1995). Expression of pIBV21, however, resulted in the detection of a protein migrating in SDS-PAGE much more slowly than the $125 \mathrm{kDa}$ protein species (Figure 3). The apparent molecular weight of approximately $155 \mathrm{kDa}$ of this product suggested that it is a fusion protein comprising the $125 \mathrm{kDa}$ protein and the product encoded by the IBV sequence from nucleotide 16932 to 17630 . This result indicates that mutation of the $\mathrm{Q}^{1491(\mathrm{~b})}$ residue to an $\mathrm{M}$ blocked the cleavage occurred at this position.

\subsection{Analyses of the Putative $Q^{2350}-S^{2351}$ and $Q^{2012}-S^{2013}$ Cleavage Sites}

During the course of studying the ORF1b expression, we have consistently observed a very low level of expression of constructs covering the $3 \mathrm{C}$-like proteinase domain and the complete ORF1b sequence. In order to analyse the two putative cleavage sites $\left(Q^{2350}\right.$ $\mathrm{S}^{2351}$ and $\mathrm{Q}^{2012}-\mathrm{S}^{2013}$ ) located in the $\mathrm{C}$-terminal one third region of the $1 \mathrm{~b}$ polyprotein, cotransfection approaches were used. As shown in Figure 4a, expression of plasmid pIBV1b5, which covers the IBV sequences from nucleotide 16932 to 20490 , led to the synthesis of a $140 \mathrm{kDa}$ polyprotein, representing the full-length product encoded by this construct. Once again, no processing of this polyprotein to smaller products were observed (Figure 4a). However, co-transfection of pIBV1b5 with pIBV3C, a plasmid containing the whole $3 \mathrm{C}$-like proteinase domain, resulted in the detection of five protein species. In addition to the $140 \mathrm{kDa}$ full-length product, four other protein species with apparent molecular 
weights of approximately $105 \mathrm{kDa}, 77 \mathrm{kDa}, 42 \mathrm{kDa}$ and $35 \mathrm{kDa}$, respectively, were also detected (Figure 4a). To reveal the identities of these products, plasmid pIBV1b4, which contains the IBV sequence from nucleotide 18930 to 20874, was expressed in Vero cells. As shown in Figure 4a, transfection of pIBV1b4 alone led to the synthesis of a polypeptide of approximately $60 \mathrm{kDa}$, consistent with the calculated full-length product of $60 \mathrm{kDa}$

A
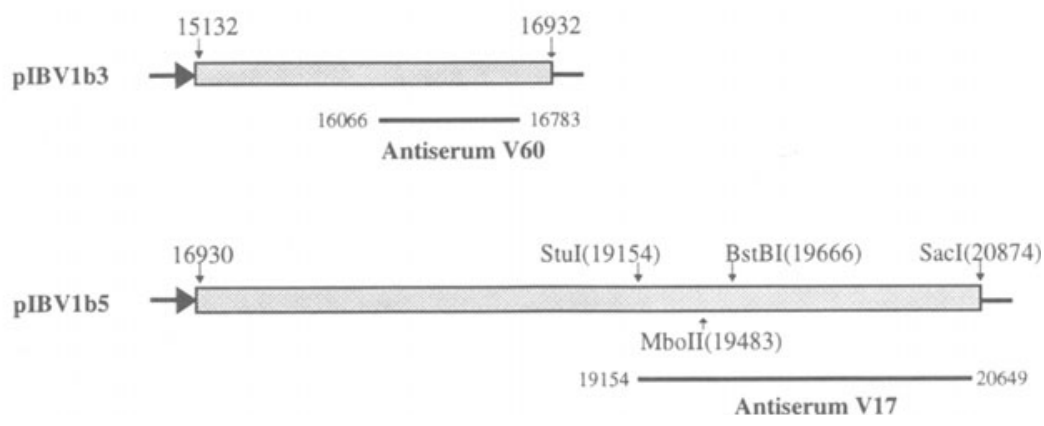

B

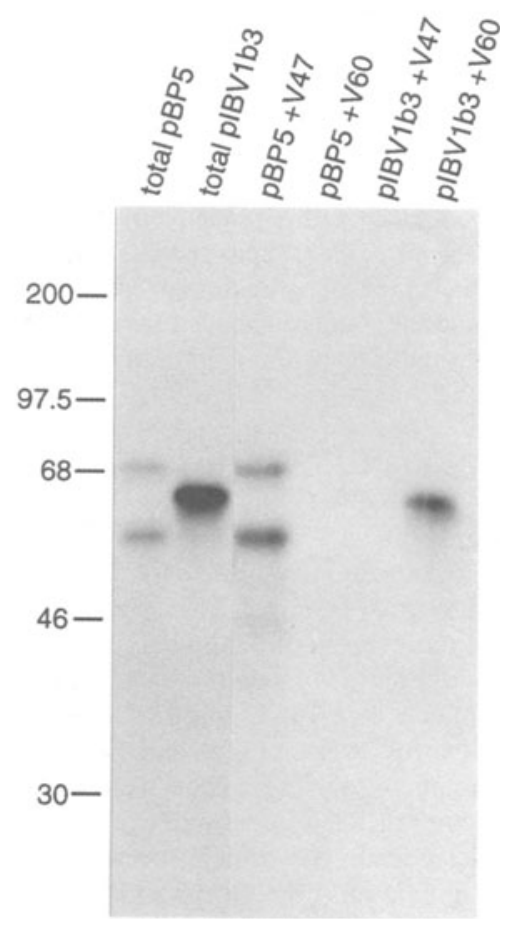

Figure 1. (A). Diagram showing IBV sequences present in plasmids pIBVIb3 and pIBV $1 \mathrm{~b} 5$, and the sequences used to raise antisera V17 and V60. Also shown are the restriction sites used to linearise pIBV1b5. (B). Testing of the reactivities of antiserum $\mathrm{V} 60$ to the in vitro synthesised target polypeptides. The polypeptides were transcribed and translated from $\mathrm{pBP} 5$ and $\mathrm{pIBV} 1 \mathrm{~b} 3$ in reticulocyte lysate with the TnT coupled translation system (Promega). Plasmid DNA was added to reticulocyte lysate at approximately $200 \mu \mathrm{g} / \mathrm{ml}$. $\left[{ }^{35} \mathrm{~S}\right]$ methionine-labelled translation products were separated on an SDS$12.5 \%$ polyacrylamide gel directly or after immunoprecipitation with either antiserum V47, which recognises the IBV sequence encoded between nucleotides 11488 and 12600 (Liu et al., 1994), or antiserum V60, and detected by fluorography. Numbers indicate molecular mass in kilodaltons. Plasmid pBP5 covers the IBV sequence from nucleotide 10752 to 12600 (Liu et al., 1994). (C). Testing of the reactivities of antiserum V17 to the in vitro synthesised target polypeptides. The polypeptides were transcribed and translated from SacI-, BstBI-, MbolIand StuI-digested pIBVIb5 in reticulocyte lysate with the TnT translation system, and were separated on an SDS- $12.5 \%$ polyacrylamide gel directly or after immunoprecipitation with antiserum V17. 


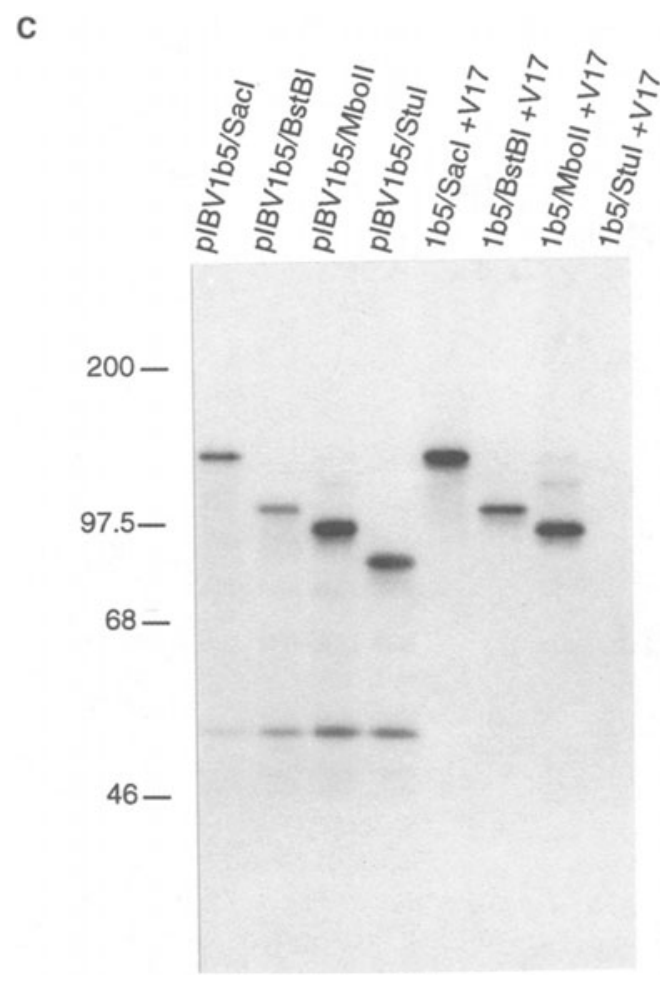

Figure 1C.

encoded by this construct. As expected, two additional products with apparent molecular weights of $25 \mathrm{kDa}$ and $35 \mathrm{kDa}$, respectively, were produced from co-expression of pIBV $1 \mathrm{~b} 4$ with pIBV3C (Figure $4 \mathrm{a}$ ). The $35 \mathrm{kDa}$ protein co-migrates with the $35 \mathrm{kDa}$ protein produced from the co-expression of pIBV 1 b5 and pIBV3C (Figure 4a), indicating that they are the same cleavage products from the $\mathrm{C}$-terminal region of the $1 \mathrm{~b}$ polyprotein.

To confirm further if cleavage did occur at the $Q^{2350}-S^{2351}$ cleavage site, substitution of the $\mathrm{Q}^{2350}$ residue with an $\mathrm{E}$ was produced by site-directed mutagenesis using the DNA template prepared from pIBV1b5, giving a mutant construct pIBV1b5Q ${ }^{2350(1 b)}$-E. Expression of pIBV1b5Q ${ }^{2350(\mathrm{lb})}-\mathrm{E}$ in Vero cells resulted in the synthesis, once again, of the fulllength $140 \mathrm{kDa}$ polyprotein (Figure $4 \mathrm{a}$ ). Co-expression of pIBV1b5Q ${ }^{2350(1 \mathrm{~b})}$-E and pIBV3C led to the formation of a polypeptide co-migrating with the $77 \mathrm{kDa}$ protein detected from co-transfection of pIBV1b5 and pIBV3C (Figure 4a). No other cleavage products were detected (Figure $4 \mathrm{a}$ ), suggesting that mutation of the $\mathrm{Q}^{2350}$ residue to $\mathrm{E}$ did block the cleavage occurred at this position. These results confirm that the $\mathrm{Q}^{2350}-\mathrm{S}^{2351}$ dipeptide bond is responsible for releasing the $\mathrm{N}$-terminus of the $35 \mathrm{kDa}$ and the C-terminus of the $42 \mathrm{kDa}$ proteins. The $77 \mathrm{kDa}$ protein detected from co-expression of pIBV1b5 and pIBV3C is therefore representing an intermediate cleavage product encoded by the IBV sequence from nucleotide 18496 to 20414. 


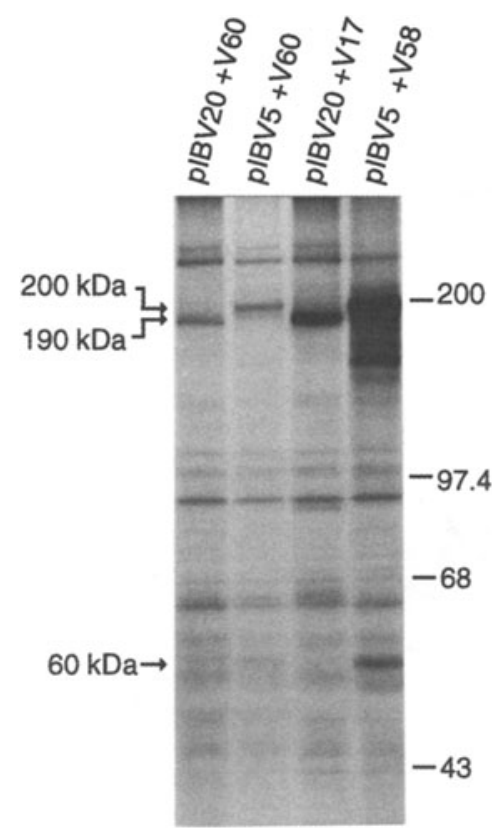

Figure 2. Analysis of transiently expressed mRNAl products from transfection with plasmids pIBV5 and pIBV20, using the vaccinia virus-T7 expression system. Cells were labelled with $\left[{ }^{35} \mathrm{~S}\right]$ methionine, lysates were prepared, and polypeptides were either analysed directly, or immunoprecipitated with either antiserum V17, V58 or V60. Polypeptides were separated on an SDS- $12.5 \%$ polyacrylamide gel, and detected by fluorography. HMW-high molecular weight markers (numbers indicate kilodaltons).

Substitution of the $\mathrm{Q}^{2012}$ residue of the predicted $\mathrm{Q}^{2012}-\mathrm{S}^{2013}$ cleavage site with an $\mathrm{E}$ was subsequently made by site-directed mutagenesis, giving the mutant construct pIBV1b5Q ${ }^{2012}$-E. Co-expression of this plasmid with pIBV3C led to the synthesis of the full-length $140 \mathrm{kDa}$ protein (Figure $4 \mathrm{~b}$ ). In addition, two polypeptides co-migrating, respectively, with the $105 \mathrm{kDa}$ and the $35 \mathrm{kDa}$ proteins detected from the co-expression of pIBV1b5 and pIBV3C, were also detected (Figure $4 \mathrm{~b}$ ). No $42 \mathrm{kDa}$ and $77 \mathrm{kDa}$ proteins, however, were observed (Figure $4 \mathrm{~b}$ ). These results indicate that mutation of the $\mathrm{Q}^{2012}$ residue to $\mathrm{E}$ abolished the cleavage occurred at this position.

\section{DISCUSSION}

We have recently reported that an ORF 1a-encoding proteinase of the picornavirus $3 \mathrm{C}$ proteinase group is responsible for cleavage of the polyproteins encoded by mRNA 1 to a $10 \mathrm{kDa}$ and a $100 \mathrm{kDa}$ mature viral products (Liu et al., 1994; Liu et al., 1997). Deletion and site-directed mutagenesis studies demonstrated that the $100 \mathrm{kDa}$ protein was encoded by IBV sequence from nucleotide 12313 to 15131 (Liu et al., 1994; Liu and Brown, 1995). Two Q-S dipeptide bonds, encoded by the ORF la sequence from nucleotide 12310 to 12315 , and by ORF $1 \mathrm{~b}$ from nucleotide 15129 to 15134 , respectively, were identified to be the cleavage sites responsible for releasing the $100 \mathrm{kDa}$ protein from the $1 \mathrm{a} / \mathrm{lb}$ fusion polyprotein (Liu and Brown, 1995). In this report, we show that the 3C-like proteinase is also able to mediate cleavage at three other sites located in the ORF $1 \mathrm{~b}$ polyprotein, resulting in the releasing of four more cleavage products approximately $65 \mathrm{kDa}, 63 \mathrm{kDa}, 42$ $\mathrm{kDa}$ and $35 \mathrm{kDa}$, respectively. 
Among the five protein species identified in this study, only the $100 \mathrm{kDa}$ protein has actually been detected from IBV-infected cells (Liu et al., 1994). Attempts were made to detect the rest four protein species in virus-infected cells, but were unsuccessful so far. It is currently uncertain if these proteins represent genuine viral products. However, as important functional domains, such as the metal-binding and RNA helicase domains, were predicted to be located in these proteins, some of them may be essential for the replication of viral RNA. Failure to detect these products may simply reflect the rapid degradation of these products in virus-infected cells during the virus infection cycle. Alternatively, complex mechanisms may be involved in regulation of the expression and accumulation of these products. Further investigations are underway to explore these possibilities.

Our previous mutagenesis data demonstrated that the $\mathrm{Q}$ residue of a Q-S cleavage site is very sensitive to substitution mutations. Substitution of the $Q$ residue with an $E$ totally block the cleavage occurred at the corresponding site (Liu and Brown, 1995). Substitution of the $\mathrm{Q}$ residue with an $\mathrm{M}$ also blocks the cleavage occurred at a $\mathrm{Q}-\mathrm{G}$ dipeptide bond. The $\mathrm{S}$ residue, however, is more tolerant to similar substitution mutations. Substitution of the $\mathrm{S}$ residue with either an A or S does not inhibit the cleavage (Liu and Brown, 1995). It seems that a wide range of Q-X (X represents any amino acid residue) dipeptide bonds might be used by the $3 \mathrm{C}$-like proteinase domain to release mature viral products. To support this hypothesis, we have recently identified a Q-N dipeptide bond responsible for the release of a $10 \mathrm{kDa}$ mature viral product from the la polyprotein (Liu et al., 1997).

Figure 3. Mutational analysis of the C-terminal cleavage site of the putative metal-binding and RNA helicase protein. Plasmids were transiently expressed in Vero cells, using the vaccinia virus-T7 expression system. The transfected cells were labelled with $\left[{ }^{35} \mathrm{~S}\right]$ methionine, lysates were prepared, and polypeptides were either analysed directly, or immunoprecipitated with antiserum V58. Polypeptides were separated on an SDS- $12.5 \%$ polyacrylamide gel, and detected by fluorography. HMW-high molecular weight markers (numbers indicate kilodaltons).

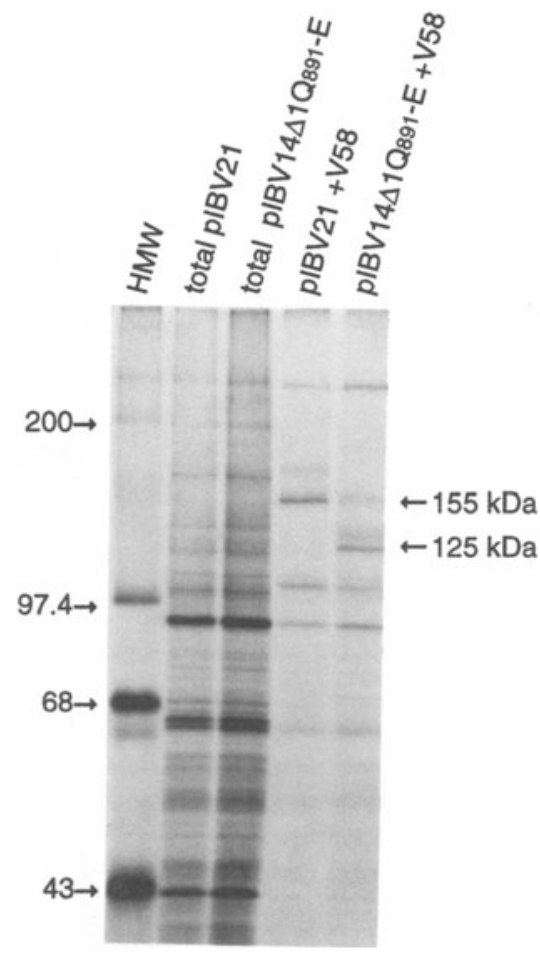




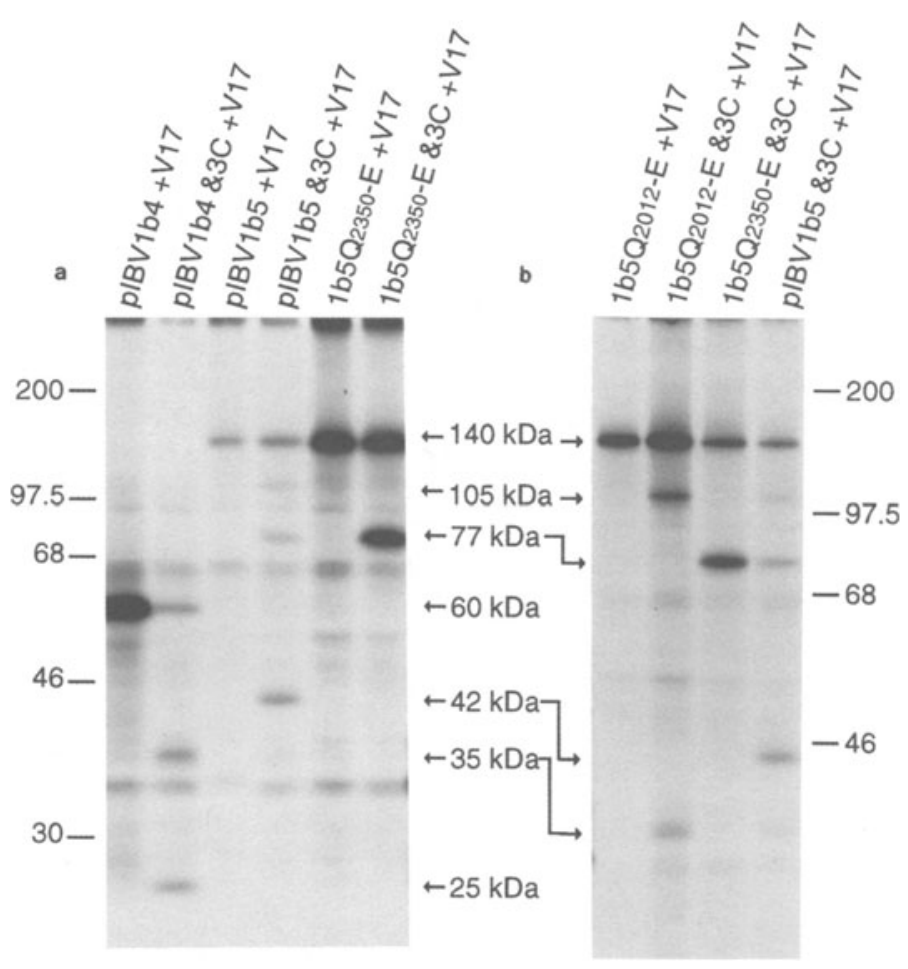

Figure 4. Analysis of transiently expressed products from pIBV1b4- and pIBV1b5-transfected Vero cells (a), and mutational analyses of the predicted $\mathrm{Q}^{2350(1 \mathrm{~b})} \mathrm{S}^{2351(1 \mathrm{~b})}$ (a) and $\mathrm{Q}^{2012(1 \mathrm{~b})} \mathrm{S}^{2013(\mathrm{bb})}$ cleavage sites (b). The transfected cells were labelled with $\left[{ }^{35} \mathrm{~S}\right]$ methionine, lysates were prepared, and polypeptides were either analysed directly, or immunoprecipitated with antiserum V17. Polypeptides were separated on an SDS- $12.5 \%$ polyacrylamide gel, and detected by fluorography. HMW-high molecular weight markers (numbers indicate kilodaltons).

Systematic mutagenesis of the cleavage dipeptides and their context is required to address this issue further.

\section{REFERENCES}

Fuerst, T. R., Niles, E. G., Studier, F. W., and Moss, B., 1986, Eukaryotic transient-expression system based on recombinant vaccinia virus that synthesizes bacteriophage T7 RNA polymerase, Proc. Natl. Acad. Sci. USA 83: $8122-8127$.

Gorbalenya, A. E., Koonin, E. Y., Donchenko, A. P., and Blinov, V. M., 1989, Coronavirus genome: prediction of putative functional domains in the non-structural polyprotein by comparative amino acid sequence analysis, Nuc. Ac. Res. 17: 4847-4860.

Laemmli, U. K., 1970, Cleavage of structural proteins during the assembly of the bacteriophage T4, Nature (London) 227: $680-685$. 
Lee, H-J., Shieh, C-K., Gorbalenya, A. E., Koonin, E. V., Monica, N. L., Tuler, J., Bagdzhadzhyan, A., and Lai, M. M. C., 1991, The complete sequence (22 kilobases) of murine coronavirus gene 1 encoding the putative proteases and RNA polymerase, Virology 180: 567-582.

Liu, D. X., and Brown, T. D. K., 1995, Characterization and mutational analysis of an ORF-1a-encoding proteinase domain responsible for proteolytic processing of the infectious bronchitis virus $1 \mathrm{a} / 1 \mathrm{~b}$ polyprotein, $V_{i}$ rology 209: 420-427.

Liu, D. X., Brierley, I., Tibbles, K. W., and Brown, T. D. K., 1994, A 100-kilodalton polypeptide encoded by open reading frame (ORF) $1 \mathrm{~b}$ of the coronavirus infectious bronchitis virus is processed by ORF 1a products, $J$. Virol. 68: 5772-5780.

Liu, D. X., Tibbles, K. W., Cavanagh. D., Brown, T. D. K., and Brierley, I., 1995, Identification, expression, and processing of an $87-\mathrm{kDa}$ polypeptide encoded by ORF la of the coronavirus infectious bronchitis virus, $\mathrm{Vi}$ rology 208: 48-57.

Liu, D. X., Xu, H. Y., and Brown, T. D. K., 1997, Proteolytic processing of the coronavirus infectious bronchitis virus la polyprotein: identificaiton of a $10 \mathrm{kDa}$ polypeptide and determination of its cleavage sites, $\mathrm{J}$. $\mathrm{V}$ rol. 71: 1814-1820. 